\title{
Magnetoencephalography Reveals Slowing of Resting Peak Oscillatory Frequency in Children Born Very Preterm
}

\author{
SAM M. DOESBURG, URS RIBARY, ANTHONY T. HERDMAN, ALEXANDER MOISEEV, TERESA CHEUNG, \\ STEVEN P. MILLER, KENNETH J. POSKITT, HAL WEINBERG, MICHAEL F. WHITFIELD, ANNE SYNNES, \\ AND RUTH E. GRUNAU
}

\begin{abstract}
Department of Diagnostic Imaging [S.M.D.], The Hospital for Sick Children, Toronto M5G 1X8, Canada; Department of Psychology [U.R., H.W.], Department of Physics [T.C.], Simon Fraser University, Burnaby V5A 1S6, Canada; Department of Audiology and Speech Sciences [A.T.H.], University of British Columbia, Vancouver V6T 1Z3, Canada; Down Syndrome Research Foundation [A.M., T.C.], Burnaby, V5B 4J8, Canada; Department of Pediatrics [S.P.M., M.F.W., A.S., R.E.G.], University of British Columbia, Vancouver V6H 3V4, Canada; Department of Radiology [K.J.P.], University of British Columbia, Vancouver V5Z 4E3, Canada
\end{abstract}

\begin{abstract}
Resting cortical activity is characterized by a distinct spectral peak in the alpha frequency range. Slowing of this oscillatory peak toward the upper theta-band has been associated with a variety of neurological and neuropsychiatric conditions and has been attributed to altered thalamocortical dynamics. Children born very preterm exhibit altered development of thalamocortical systems. To test the hypothesis that peak oscillatory frequency is slowed in children born very preterm, we recorded resting magnetoencephalography (MEG) from school age children born very preterm ( $\leq 32$ wk gestation) without major intellectual or neurological impairment and age-matched full-term controls. Very preterm children exhibit a slowing of peak frequency toward the theta-band over bilateral frontal cortex, together with reduced alpha-band power over bilateral frontal and temporal cortex, suggesting that mildly dysrhythmic thalamocortical interactions may contribute to altered spontaneous cortical activity in children born very preterm. (Pediatr Res 70: 171-175, 2011)
\end{abstract}

$\mathrm{U}$ nderstanding neurodevelopmental alterations in very preterm children ( $\leq 32 \mathrm{wk} \mathrm{GA})$ is of increasing importance due to improved survival rates in recent decades, together with the prevalence of cognitive, behavioral, and motor deficits in this group (1) and the increasing incidence of developmental difficulties in this vulnerable population (2). Even in the absence of major neurological impairment and when intelligence is broadly normal, children born very preterm frequently exhibit selective cognitive deficits at school age, such as in executive function and visual processing (3-7). Children, adolescents, and adults born very preterm have also been shown to activate different neural networks during cognitive and perceptual processing (8-10). Considerable advances have been made in relating structural brain alterations associated with very preterm birth to developmental outcome (11-13). As previous imaging research on brain development in children born very prematurely

Received November 15, 2010; accepted February 23, 2011.

Correspondence: Sam M. Doesburg, Ph.D., Department of Diagnostic Imaging, The Hospital for Sick Children, 555 University Avenue, Toronto, ON M5G 1X8, Canada; e-mail: sam.doesburg@sickkids.ca

Supported by grant RO1 HD039783 from the Kennedy Shriver Institute of Child Health and Human Development (NICHD/NIH) [R.E.G.], the Michael Smith Foundation for Health Research [S.M.D.], the Child and Family Research Institute [S.M.D., R.E.G.], The Canadian Institutes for Health Research [S.M.D., R.E.G., S.P.M.], the Human Early Learning Partnership [R.E.G.], and the BC Leading Edge Endowment Fund [U.R.]. has predominantly focused on structure, however, very little is known about cortical oscillatory activity in this population. This represents an important question as cortical oscillations play a central role in the generation of cognition and perception (14-16) and age-related changes in cortical oscillations reflect cognitive development $(17,18)$. The generation of cortical oscillatory activity relevant to cognition and perception has been shown to depend critically on thalamic input (19).

Several lines of research have indicated altered development of thalamocortical systems in children born very preterm. White matter damage is the prevalent form of brain injury in this vulnerable population, and advanced imaging techniques have identified abnormal white matter connectivity in preterm children who do not exhibit brain injury on conventional MRI $(20,21)$. White matter alterations in very preterm children include abnormal development of thalamocortical connections, even in the absence of focal lesions as identified by conventional MR imaging (22), and when developmental outcome is normal (23). The 24-32 wk gestational period corresponding to very premature birth is also characterized by the prominence of the transient cortical subplate zone, which reaches four to five times the size and thickness of the cortical plate (24), and plays a critical role in the development of thalamocortical connections $(25,26)$. Moreover, investigation of resting state network dynamics using hemodynamic measures of functional connectivity (fcMRI) has demonstrated that very preterm infants scanned at term equivalent age exhibit reduced functional connectivity between cortex and thalamus, relative to full-term controls (27).

Previous magnetoencephalographic (MEG) research has established that disordered thalamocortical interactions are commonly associated with a slowing of the $\sim 10 \mathrm{~Hz}$ peak cortical oscillation from the alpha-band $(8-14 \mathrm{~Hz})$ toward the slower theta $(4-7 \mathrm{~Hz})$ frequency range (28). Animal research has demonstrated that thalamic input and thalamocortical interactions are critical for the generation of alpha- and thetaband oscillations in the cerebral cortex and that disruption of thalamic and thalamocortical systems can induce deceleration

Abbreviation: MEG, magnetoencephalography 
of cortical alpha rhythms toward the theta-band (29-31). In humans, slowing of peak oscillatory frequency has been identified in several neurological and neuropsychiatric disorders including Alzheimer's disease, neurogenic pain, Parkinson's disease, and schizophrenia (28,32-36). This oscillatory slowing is often accompanied by reduced alpha-band activity $(33,34,37,38)$, and studies using implanted electrodes and fcMRI have confirmed the involvement of disordered thalamocortical interactions in these pathological conditions (37-41). The relationship between the development of corticothalamic connectivity and cortical alpha rhythms is further underlined by recent evidence of correlations between white matter architecture in corticothalamic systems and the parameters of alpha oscillations recorded using EEG (42).

Evidence indicating altered development of thalamocortical systems in children born very prematurely, in light of previous work implicating disordered thalamocortical activity in the slowing and reduction of cortical alpha rhythms, suggests that very preterm children may exhibit a slowing of peak oscillatory frequency and reduced alpha power. To test this hypothesis, we recorded resting neuromagnetic activity from school age children who were born very prematurely without major neurological or intellectual impairment and age-matched fullterm controls and analyzed the power spectrum of spontaneous neuromagnetic oscillations.

\section{METHODS}

Subjects. Eleven school age children born very preterm ( $\leq 32 \mathrm{wk}$; mean gestation $30.29 \mathrm{wk} ; \mathrm{SD}=2.39 \mathrm{wk}$; range $=26-32 \mathrm{wk}$ ), mean age $7.53 \mathrm{y}$ (range $=7.28-7.92 \mathrm{y} ; \mathrm{SD}=0.18 \mathrm{y}$ ) were recruited as part of a longitudinal study on the neurocognitive development of very preterm children $(43,44)$. Eleven age-matched full-term control children, mean age 7.54 y (range = $7.35-7.87 \mathrm{y} ; \mathrm{SD}=0.15 \mathrm{y}$ ), were recruited from a combination of the longitudinal study and from the community at school age. Very preterm children had a mean birth weight of $1471 \mathrm{~g}$ (range $=755-2030 \mathrm{~g}$; SD = $527 \mathrm{~g}$ ). The very preterm group comprised six girls and five boys, and the full-term group consisted of three girls and eight boys. Individual cognitive assessment was carried out using the Wechsler Intelligence Scale for Children (45), with mean full scale intelligence quotient (FSIQ) of 97.18 (15.03) for the very preterm and 108.73 (16.89) for the full-term groups, which did not differ significantly $(p=0.11)$. None of the children in the very preterm group had significant brain injury (periventricular leukomalacia or grade III-IV intraventricular hemorrhage) evident on neonatal cranial ultrasound (46). No child had any known neurological illness or major sensory, motor, or intellectual impairment. Table 1 displays clinical and birth characteristics of children in our very preterm group. As several of the full-term controls were recruited from outside the longitudinal cohort, characterization of neonatal information was not possible for this group. Informed consent was obtained from each subject and their parent. This study was approved by the Clinical Research Ethics Board of the University of British Columbia and the Research Ethics Board of the Children's \& Women's Health Centre of BC, and conforms with the conventions set out in the Declaration of Helsinki.

MEG recording. Two minutes of spontaneous eyes open data were recorded from each subject using a 151-channel whole-head MEG system (CTF systems; Port Coquitlam, Canada). Children were supine, viewed a

Table 1. Summary of clinical and birth characteristics of the very preterm group

\begin{tabular}{lc} 
GA at birth (wk) & $30.3(2.4)$ \\
Birth weight $(\mathrm{g})$ & $1471(527)$ \\
Days on mechanical ventilation & $10.55(18)$ \\
Number of skin-breaking procedures from birth to term & $93.7(89.8)$ \\
Small for GA, $n(\%)$ & $1(9)$ \\
Singleton, $n(\%)$ & $7(64)$ \\
Intraventricular hemorrhage grade I-II, $n(\%)$ & $2(18)$ \\
\hline
\end{tabular}

"happy face" which was projected onto a screen $40 \mathrm{~cm}$ above their eyes, and were monitored by a research assistant in the recording chamber to ensure that subjects maintained open eyes during recording. Data were digitized continuously at $1200 \mathrm{~Hz}$ and stored for offline analysis. Eyes closed resting state data were not recorded in addition to eyes open data due to limitations imposed by neuroimaging in special child populations, given that children were also expected to perform a cognitive task in the MEG, described elsewhere (47) and in the discussion. Fiducial coils were attached at the nasion and at left and right preauricular locations, and each coil was energized at a distinct high narrow-band frequency.

MEG analysis. To standardize head location relative to sensors, between and within subjects, dipolar source solutions were computed for each of the fiducial coils 30 times per second, thereby creating a continuous record of head position during MEG recording. MEG data were then aligned to a common position by performing an inverse solution, data rotation, and forward solution 30 times per second (48). Energized high-frequency activity emitted by the fiducial coils during recording was then removed using notch filtering and data were down sampled to $300 \mathrm{~Hz}$. The record of ocular and nonocular artifacts was removed from MEG recordings using a principal component analysis-based procedure (49). Data were then transformed from axial gradiometer to planar gradiometer sensor space (50) using routines implemented in the FieldTrip software package (http://www.ru.nl/fcdonders/fieldtrip). This method has previously been used to accurately assess the topography of cortical oscillations in sensor-level analyses using 151-channel CTF MEG systems (51). This conversion was performed so that signals correspond more directly to cortical activity directly underlying each sensor, as planar gradiometers exhibit more spatially restricted lead fields than their axial counterparts.

To determine the spectral density of cortical activity, data from each sensor were filtered at $1-\mathrm{Hz}$ intervals, using methods established in previous studies for the accurate measurement of spectral activity (51-53), from 6 to $60 \mathrm{~Hz}$ (passband equals filtered frequency $\pm 0.05 \mathrm{~Hz}$ ). This frequency range was chosen as previous results indicate that the slowing of alpha rhythms in neurological and neuropsychiatric conditions produces a peak in the upper theta or lower alpha frequency range $(28,32,36-38)$ and to distinguish this peak from lower frequency theta activity which is distinct from the alpha peak. Power was then calculated for each data point in the 120 -s filtered time series for each analyzed frequency and sensor and then averaged across all time points. This provided a single value for each subject representing the average power of neuromagnetic oscillations at each frequency and sensor during the 2-min recording section. To examine the topography of oscillatory changes, data were averaged across sensors in within-regional sensor groupings and midline electrodes were excluded (Fig. 1). These regional sensor groupings were selected because they i) have been successfully used to reveal alterations in spontaneous oscillatory activity in clinical populations using a 151-channel CTF system $(54,55)$, ii) conform to regional groupings designated by the system manufacturer, iii) correspond roughly to underlying cortical regions, and iv) allow exploration of topography while limiting the number of statistical comparisons. This averaging produced power values at each analyzed frequency within each regional sensor grouping for each subject. Alpha power was calculated by averaging power across $8-14 \mathrm{~Hz}$ values for each sensor grouping for each subject, as this frequency range encapsulates the alpha-band. One-tailed $t$ tests were used to analyze group differences in peak oscillatory frequency and oscillatory power within each regional sensor grouping, as a priori hypotheses regarding the direction of effects were based on oscillatory changes in other special populations with analogous physiological alterations.

\section{RESULTS}

MEG results. Inspection of global spectral activity (averaged across all 151 sensors) indicated a reduction of the alpha peak, together with a slowing of peak frequency, in very preterm children, relative to full-term controls (Fig. 2). To investigate the topography of observed alterations in the spectral density of resting MEG in very preterm children and perform statistical tests for group differences, we investigated group differences in peak oscillatory frequency and alpha power $(8-14 \mathrm{~Hz})$ within each regional sensor grouping. This revealed significantly slower peak oscillatory frequency in very preterm children (Fig. 3A) which was concentrated and statistically significant over bilateral frontal cortex $(p=0.039$ left; $p=0.0031$ right). All analyzed regions trended toward 


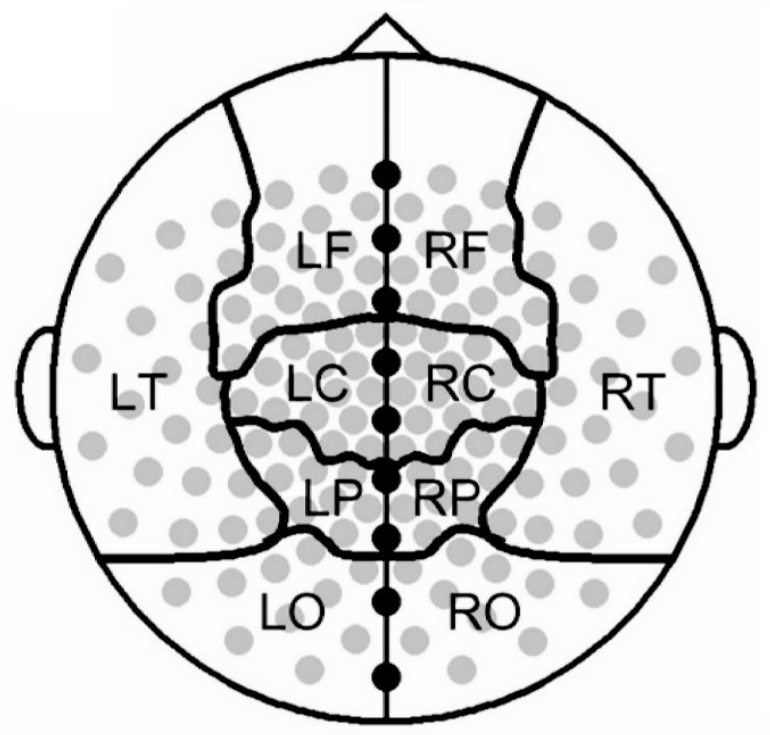

Figure 1. The sensor montage and regional groupings. Gray circles represent sensors used in the analysis of resting MEG by cortical sector, black circles denote midline sensors excluded from regional analyses, and black lines denote the boundaries of cortical regions in the sensor level analysis. Letters indicate cortical regions: L, left; R, right; F, frontal; C, central; T, temporal; $\mathrm{P}$, parietal; O, occipital.

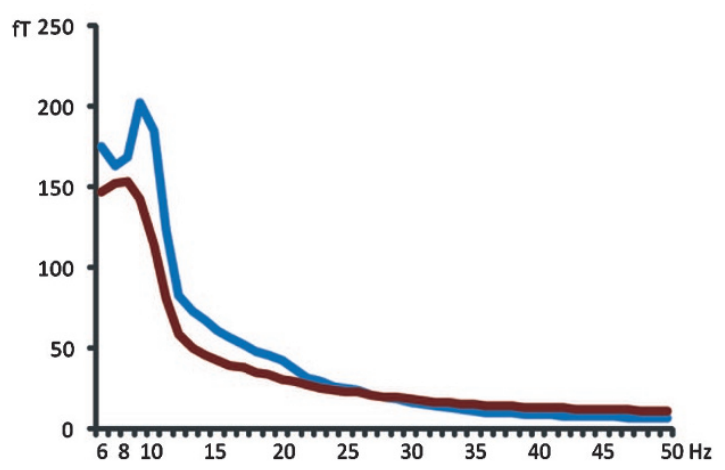

Figure 2. Global power spectrum of spontaneous MEG activity for very preterm children and full-term controls averaged over all 151 sensors. The blue line represents the global power spectrum for the full-term controls and the red line represents that of the very preterm children. oscillatory slowing except for the left occipital area (Fig. 3A). Alpha-band power in very preterm children was significantly reduced over bilateral frontal ( $p=0.047$ left; $p=0.019$ right) and temporal cortex ( $p=0.015$ left; $p=0.0028$ right) and trended toward reduced activity in all other analyzed regions (Fig. 3B). Additional statistical information regarding peak oscillatory frequency and resting alpha power within each analyzed region is presented in Table 2 .

\section{DISCUSSION}

We demonstrate slowing of resting peak oscillatory frequency and reduced alpha-band power in very preterm children, providing the first evidence of altered spontaneous neuromagnetic activity in this vulnerable population. Slowing of the alpha peak toward the theta frequency range has been identified in a variety of pathological conditions in adults $(28,32-36)$ and is often accompanied by a reduction in alpha-band power $(33,34,37,38)$. Our findings provide a novel demonstration of a mild slowing of peak oscillatory frequency in a clinical population without major neurological or intellectual impairment. The findings of this study add to accumulating evidence that children born very preterm who escape significant neonatal brain injury and have neurocognitive function in the broadly normal range, nonetheless express altered cortical activity relevant to cognition. Such observations are consistent with previous work showing that very preterm infants express altered event-related potentials in response to visual, auditory, and somatosensory stimulation $(56,57)$ and more recent evidence that such responses are altered in school age children born prematurely (58) even in the absence of major impairment (59). The results of this study build upon recent functional imaging results showing altered cortical network dynamics in individuals born very prematurely $(8-10)$ by demonstrating altered expression of cortical oscillations known to be critical for the generation of cognitive processes (14-16) in this population. Using a partially overlapping group of school age children born very prematurely drawn from the same longitudinal cohort $(43,44)$, we previously demonstrated reduced interregional alpha-band phase locking during visual short-term memory retention in these children together with increased interhemishperic long-range theta-band synchronization (47), suggesting that reduction and slowing of alpha oscillations may play a critical role in the altered neurocognitive development of very
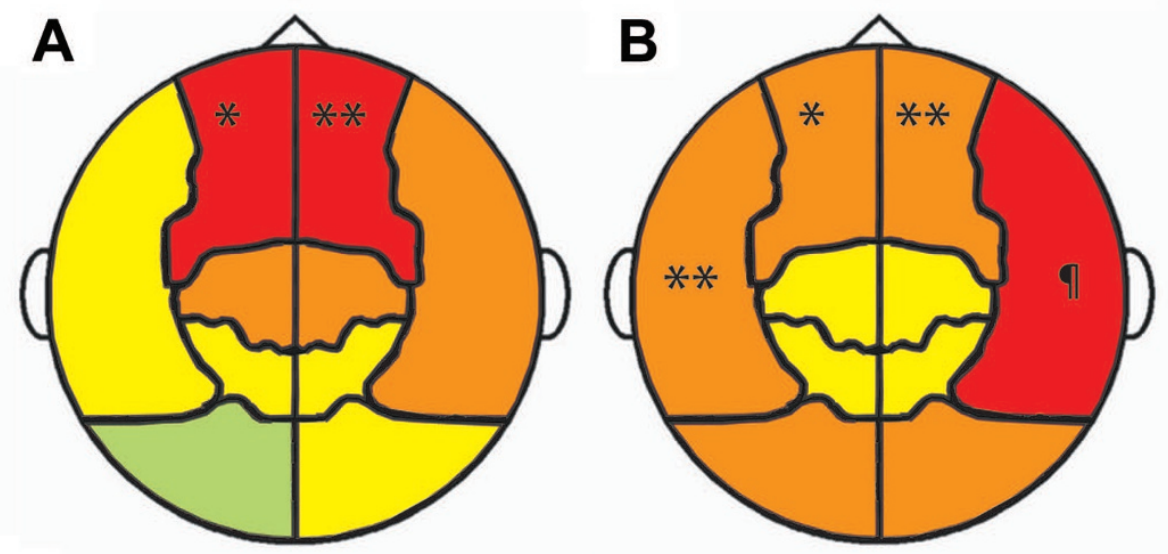

Figure 3. (A) Shift of peak oscillatory frequency in very preterm children, relative to full-term controls, in each cortical region. The magnitude of frequency shifts is denoted by color $(\mathrm{red},-1$ to $-2 \mathrm{~Hz}$; orange, -0.5 to $-1 \mathrm{~Hz}$; yellow, 0 to $-0.5 \mathrm{~Hz}$; green, 0 to $+0.5 \mathrm{~Hz}$ ) and statistically significant group differences are labeled $(* p<$ $0.05 ; * * p<0.005)$. (B) Reduction of alpha $(8-14 \mathrm{~Hz})$ power in children born very preterm, relative to full-term controls, in each cortical region. Colors represent the magnitude of group differences (red, -50 to -75 femptotesla (fT); orange, -25 to $-50 \mathrm{fT}$; and yellow, 0 to -25 fT) and statistically significant differences are indicated $(* p<0.05 ; * * p<0.02 ; \rrbracket \mid p<0.003)$. 
Table 2. Mean and standard deviation of peak oscillatory frequency and alpha (8-14 Hz) power in femptotesla (fT) within each regional sensor grouping for both the preterm and full-term groups

\begin{tabular}{|c|c|c|c|c|}
\hline \multicolumn{3}{|c|}{ Peak oscillatory frequency $(\mathrm{Hz})$} & \multicolumn{2}{|c|}{ Alpha power (fT) } \\
\hline & Full-terms & Preterms & Full-terms & Preterms \\
\hline Left frontal & $7.82(1.89)$ & $6.64(0.92) *$ & $84.05(33.29)$ & $57.85(36.42)^{*}$ \\
\hline Left temporal & $8.36(1.80)$ & $7.91(1.64)$ & $148.32(50.68)$ & $98.67(49.13)$ \\
\hline Left central & $8.55(1.56)$ & $7.73(1.68)$ & $106.60(59.42)$ & $90.01(47.93)$ \\
\hline Left parietal & $8.45(1.37)$ & $8.36(1.69)$ & $111.82(95.91)$ & $100.25(146.64)$ \\
\hline Left occipital & $8.27(1.27)$ & $8.67(1.43)$ & $156.04(108.58)$ & $101.67(49.17)$ \\
\hline Right frontal & $8.64(1.81)$ & $6.73(1.01) \dagger$ & $47.93(118.69)$ & $41.40(76.17) \dagger$ \\
\hline Right temporal & $8.10(1.97)$ & $7.18(1.53) \dagger$ & $194.61(42.81)$ & $122.95(55.25)$ 本 \\
\hline Right central & $8.55(1.80)$ & $7.82(1.60)$ & $122.92(53.30)$ & $105.60(117.66)$ \\
\hline Right parietal & $8.77(1.56)$ & $8.55(1.51)$ & $92.93(51.46)$ & $69.68(35.53)$ \\
\hline Right occipital & $8.50(1.13)$ & $8.00(1.55)$ & $147.83(84.36)$ & $105.83(57.38)$ \\
\hline
\end{tabular}

Statistically significant group differences are in bold.

$* p<0.05$.

$\dagger p<0.025$.

$\ddagger p<0.005$.

preterm children. This outlook is underscored by findings indicating that alpha rhythms play an important role in cognition and perception $(60,61)$ and age-related changes in alpha responses have been demonstrated during cognitive and perceptual processing in children $(18,62-64)$.

During the neonatal period corresponding to premature birth, there is a rapid shift toward relatively more high-frequency EEG activity, which includes decreasing theta oscillations (65), indicating that neural mechanisms underlying cortical rhythms are undergoing a critical developmental phase in the perinatal period corresponding to premature birth (66). Although the density of spectral power recorded from the cortex of very preterm infants using EEG becomes very similar to that of full-term infants at term age (67), a progressive shift toward higher frequency oscillations continues throughout normal childhood development (68). This change proceeds along a posterior-to-anterior axis (69), and progressive increases in the expression of alpha rhythms are observed throughout childhood (68). Accordingly, oscillatory slowing and reduced alpha-band power in very preterm children observed in this study could be conceived as a delay in the development of normal brain maturation. However, the finding that the ratio of low-frequency to high-frequency oscillations is increased in young adults born with extremely low birth weight and very prematurely (70) suggests that slowed oscillatory activity is either permanent or extremely long lasting and is embedded among networks across a wider frequency scale. The relationship between neonatal experience and altered cortical activity in school age children born very preterm is an important question for future research, as it is possible that altered neuromagnetic oscillations in these children are due, at least in part, to regulatory challenges associated with exposure to a stressful extrauterine environment $(3,71)$ during a period wherein neural systems relevant to the generation of cortical oscillatory activity are undergoing major development $(65,66,72,73)$.

\section{CONCLUSION}

We demonstrate that the peak oscillatory frequency of resting cortical oscillations is slowed in school age children born very preterm, even in the absence of major neurological or intellectual impairment. This constitutes the first evidence of altered spontaneous neuromagnetic activity in this vulnerable population. Slowing of the alpha rhythms toward the theta-band has been previously identified in several neurological and neuropsychiatric populations and has been attributed to disordered thalamocortical dynamics. The results of this study suggest that altered thalamocortical development in very preterm children may contribute to altered expression of oscillatory brain activity in this vulnerable population.

Acknowledgments. We thank Dr. Ivan Cepeda and Gisela Gosse for coordinating the study, and Katia Jitlina and Amanda Degenhardt for their help in data collection. We thank Diederick Stoffers for help with figures.

\section{REFERENCES}

1. Behrman RE, Butler AS; Institute of Medicine (U.S.) Committee on Understanding Premature Birth and Assuring Healthy Outcomes 2007 Preterm Birth: Causes, Consequences, and Prevention. National Academies Press, Washington DC

2. Roberts G, Anderson PJ, De Luca C, Doyle LW; Victorian Infant Collaborative Study Group 2010 Changes in neurodevelopmental outcome at age eight in geographic cohorts of children born at 22-27 weeks' gestational age during the 1990s. Arch Dis Child Fetal Neonatal Ed 95:F90-F94

3. Grunau R 2002 Early pain in preterm infants. A model of long-term effects. Clin Perinatol 29:373-394

4. Marlow N, Hennessy EM, Bracewell MA, Wolke D 2007 Motor and executive function at 6 years of age after extremely preterm birth. Pediatrics 120:793-804

5. Mulder H, Pichford NJ, Haggar MS, Marlow N 2009 Development of executive function and attention in preterm children: a systematic review. Dev Neuropsychol 34:393-421

6. Rickards AL, Kelly EA, Doyle LW, Callanan C 2001 Cognition, academic progress, behavior and self-concept at 14 years of very low birth weight children. J Dev Behav Pediatr 22:11-18

7. Taylor HG, Minich NM, Klein N, Hack M 2004 Longitudinal outcomes of very low birth weight: neuropsychological findings. J Int Neuropsychol Soc 10:149-163

8. Gozzo Y, Vohr B, Lacadie C, Hampson M 2009 Alterations in neural connectivity in preterm children at school age. Neuroimage 48:458-463

9. Narberhaus A, Lawrence E, Allin MP, Walshe M, McGuire P, Rifkin L, Murray R, Nostari C 2009 Neural substrates of visual paired associates in young adults with a history of very preterm birth: alterations in fronto-parieto-occipital networks and caudate nucleus. Neuroimage 47:1884-1893

10. Schafer RJ, Lacadie C, Vohr B, Kesler SR, Schneider KC, Pugh KR, Makuch RW, Reiss AL, Constable RT, Ment LR 2009 Alterations in functional connectivity for language in prematurely born adolescents. Brain 132:661-670

11. Peterson BS, Vohr B, Staib LH, Cannistraci BA, Dolberg A, Katz KH, Westerveld M, Sparrow S, Anderson AW, Duncan CC, Makuch RW, Gore JC, Ment LR 2000 Regional brain volume abnormalities and long-term cognitive outcome in preterm infants. JAMA 284:1939-1947 
12. Hart AR, Whitby EW, Griffiths PD, Smith MF 2008 Magnetic resonance imaging and developmental outcome following preterm birth: review of current evidence. Dev Med Child Neurol 50:655-663

13. Ment LR, Hirtz D, Hüppi PS 2009 Imaging of biomarkers of outcome in the developing preterm brain. Lancet Neurol 8:1042-1055

14. Uhlhaas PJ, Pipa G, Lima B, Melloni L, Neuenschwander S, Nikolić D, Singer W 2009 Neural synchrony in cortical networks: history, concept and current status. Front Integr Neurosci 3:17

15. Varela F, Lachaux JP, Rodriguez E, Martinerie J 2001 The brainweb: phase synchronization and large-scale integration. Nat Rev Neurosci 2:229-239

16. Ward LM 2003 Synchronous neural oscillations and cognitive processes. Trends Cogn Sci 7:553-559

17. Benasich AA, Gou Z, Choudhury N, Harris KD 2008 Early cognitive and language skills are linked to resting frontal gamma power across the first 3 years. Behav Brain Res 195:215-222

18. Uhlhaas PJ, Roux F, Singer W, Heanschel C, Sieteanu R, Rodriguez E 2009 The development of neural synchrony reflects late maturation and restructuring of functional networks in humans. Proc Natl Acad Sci U S A 106:9866-9871

19. Ribary U 2005 Dynamics of thalamo-cortical network oscillations and human perception. Prog Brain Res 150:127-142

20. Dudink J, Kerr JL, Paterson K, Counsell SJ 2008 Connecting the developing preterm brain. Early Hum Dev 84:777-782

21. Miller SP, Ferriero DM 2009 From selective vulnerability to connectivity: insights from newborn brain imaging. Trends Neurosci 32:496-505

22. Anjari M, Srinivasan L, Allsop JM, Hajnal JV, Rutherford MA, Edwards AD, Counsell SJ 2007 Diffusion tensor imaging with tract-based spatial statistics reveals local white matter abnormalities inpreterm infants. Neuroimage 35:1021-1027

23. Dudink J, Maarten L, van Pul C, Buijs J 2007 Fractional anisotropy in white matter tracts of very-low-birth-weight infants. Pediatr Radiol 37:1216-1223

24. Kostovic I, Rakic P 1990 Developmental history of the transient subplate zone in the visual and somatosensory cortex of the macaque monkey and human brain. J Comp Neurol 297:441-470

25. Allendoerfer KL, Shatz CJ 1994 The subplate, a transient neocortical structure: it role in the development of connections between thalamus and cortex. Annu Rev Neurosci 17:185-218

26. Kostovic I, Jovanov-Milosević N 2006 Development of cerebral connections during the first 20-45 weeks' gestation. Semin Fetal Neonatal Med 11:415-422

27. Smyser CD, Inder TE, Shimony JS, Hill JE, Degnan AJ, Snyder AZ, Neil JJ 2010 Longitudinal analysis of neural network development in preterm infants. Cereb Cortex 20:2852-2862

28. Llinás RR, Ribary U, Jeanmonod D, Kronberg E, Mitra PP 1999 Thalamocortica dysrhythmia: a neurological and neuropsychiatric syndrome characterized by magnetoengephlography. Proc Natl Acad Sci U S A 96:15222-15227

29. Marini G, Ceccarelli P, Mancia M 2002 Thalamocortical dysrhythmia and the thalamic reticular nucleus in behaving rats. Clin Neurophysiol 113:1152-1164

30. Hughes SW, Crunelli V 2005 Thalamic mechanisms of EEG alpha rhythms and their pathological implications. Neuroscientist 11:357-372

31. Steriade M 2006 Grouping of brain rhythms in corticothalamic systems. Neuroscience 137:1087-1106

32. Boord P, Siddall PJ, Tran Y, Herbert D, Middleton J, Craig A 2008 Electroencephalographic slowing and reduced reactivity in neuropathic pain following spinal cord injury. Spinal Cord 46:118-123

33. Boutros NN, Arfken C, Galderisi S, Warrick J, Pratt G, Iacono W 2008 The status of spectral EEG abnormality as a diagnostic test for schizophrenia. Schizophr Res 99:225-237

34. Jeong J 2004 EEG dynamics in patients with Alzheimer's disease. Clin Neurophysiol 115:1490-1505

35. Moazami-Goudarzi M, Sarnthein J, Michels L, Moukhtieva R, Jeanmonod D 2008 Enhanced frontal low and high frequency power synchronization in the resting EEG of Parkinsonian patients. Neuroimage 41:985-997

36. Sarnthein J, Stern J, Aufenberg C, Rousson V, Jeanmonod D 2006 Increased EEG power and slowed dominant frequency in patients with neurogenic pain. Brain 129:55-64

37. Sarnthein J, Jeanmonod D 2007 High thalamocortical coherence in patients with Parkinson's disease. J Neurosci 27:124-131

38. Sarnthein J, Jeanmonod D 2008 High thalamocortical coherence in patients with neurogenic pain. Neuroimage 39:1910-1917

39. Cauda F, Sacco K, D'Agata F, Duca S, Cocito D, Geminiani G, Migliorati F, Isoardo G 2009 Low-frequency BOLD fluctuations demonstrate altered thalamocortical connectivity in diabetic neuropathic pain. BMC Neurosci 10:138

40. Sarnthein J, Morel A, von Stein A, Jeanmonod D 2005 Thalamocortical theta coherence in neurological patients at rest and during a working memory task. Int J Psychophysiol 57:87-96

41. Welsh RC, Chen AC, Taylor SF 2010 Low-frequency BOLD fluctuations demonstrate altered thalamocortical connectivity in schizophrenia. Schizophr Bull 36:713722

42. Valdés-Hernández PA, Ojeda-Gonzalez A, Martinez-Montes E, Lage-Castellanos A, Virués-Alba T, Valdés-Urrutia L, Valdes-Sosa PA 2010 White matter architecture rather than cortical surface area correlated with the EEG alpha rhythm. Neuroimage 49:2328-2339

43. Grunau RE, Haley DW, Whitfield MF, Weinberg J, Yu W, Thiessen P 2007 Altere basal cortisol levels at 3, 6, 8 and 18 months in infants born at extremely low gestational age. J Pediatr 150:151-156
44. Grunau RE, Whitfield MF, Petrie-Thomas J, Synnes AR, Cepeda IL, Keidar A, Rogers M, Mackay M, Hubber-Richard P, Johannesen D 2009 Neonatal pain, parenting stress and interaction, in relation to cognitive and motor development at 8 and 18 months in preterm infants. Pain 143:138-146

45. Wechsler D 2003 Wechsler Intelligence Scales for Children: 4th ed. (WISC-IV). Psychological Corporation, San Antonio, TX

46. Papile LA, Burstein J, Burstein R, Koffler H 1978 Incidence and evolution of subependymal and intraventricular hemorrhage: a study of infants with birth weights less than 1500 grams. J Pediatr 92:529-534

47. Doesburg SM, Ribary U, Herdman AT, Miller SP, Poskitt KJ, Moiseev A, Whitfield MF, Synnes A, Grunau RE 2011 Altered long-range alpha-band synchronization during visual short-term memory retention in children born very preterm. Neuroimage 54:2330-2339

48. Wilson H, Moiseev A, Podin S, Quraan M 2007 Continuous head localization and data correction in MEG. Int Congress Ser 1300:623-626

49. Herdman AT, Cheyne D 2009 A practical guide to MEG and beamforming. In Handy TC (ed) Brain Signal Analysis: Advances in Neuroelectric and Neuromagnetic Methods. MIT Press, Cambridge, pp 99-140

50. Bastiaansen MC, Knosche TR 2000 Tangential derivative mapping of axial MEG applied to event-related desynchronization research. Clin Neurophysiol 111:13001305

51. Mazaheri A, Nieuwenhuis IL, van Dijk H, Jensen O 2009 Prestimulus alpha and mu activity predicts failure to inhibit motor responses. Hum Brain Mapp 30:1791-1800

52. Doesburg SM, Green JJ, McDonald JJ, Ward LM 2009 Rhythms of consciousness: binocular rivalry reveals large-scale oscillatory network dynamics mediating visual perception. PLoS One 4:e6142

53. Kitajo K, Doesburg SM, Yamanaka K, Nozaki D, Ward LM, Yamamoto Y 2007 Noise-induced large-scale phase synchronization of human-brain activity associated with behavioural stochastic resonance. Europhys Lett 80:40009

54. Stoffers D, Bosboom JL, Deijen JB, Wolters EC, Stam CJ, Berendse HW 2008 Increased cortico-cortical functional connectivity in early-stage Parkinson's disease: an MEG study. Neuroimage 41:212-222

55. Stoffers D, Bosboom JL, Wolters EC, Stam CJ, Berendse HW 2008 Dopaminergic molulation of cortico-cortical functional connectivity in Parkinson's disease: an MEG study. Exp Neurol 213:191-195

56. Taylor MJ, Saliba E, Laugier J 1996 Use of evoked potentials in preterm neonates. Arch Dis Child Fetal Neonatal Ed 74:F70-F76

57. Fellman V, Kushnerenko E, Mikkola K, Ceponiene R, Leipala J, Naatanen R 2004 Atypical auditory event-related potentials in preterm infants during the first year of life: a possible sign of cognitive dysfunction? Pediatr Res 56:291-297

58. Gomot M, Bruneau N, Laurent JP, Barthélémy C, Sabilia E 2007 Left temporal impairment of auditory information processing in prematurely born 9-year-old children: an electrophysiological study. Int J Psychophysiol 64:123-129

59. O'Reilly M, Vollmer B, Vargha-Khadem F, Neville B, Connelly A, Wyatt J, Timms C, de Haan M 2010 Opthamological, cognitive, electrophysiological and MRI assessment of visual processing in preterm children without major neuromotor impairment. Dev Sci 13:692-705

60. Klimesch W, Sauseng P, Hanslmayr S 2007 EEG alpha oscillations: the inhibitiontiming hypothesis. Brian Res Rev 53:63-88

61. Palva S, Palva JM 2007 New vistas for alpha-frequency band oscillations. Trends Neurosci 30:150-158

62. Krause CM, Salminen PA, Sillanmaki L, Holopainen IE 2001 Event related desynchronization and synchronization during a memory task in children. Clin Neurophysiol 112:2233-2240

63. Xiang J, Liu Y, Wang Y, Kotecha R, Kirtman EG, Huo X, Fujiwara H, Hemasilpin N, DeGrauw T, Rose M 2009 Neuromagnetic correlated of developmental changes in endogenous high-frequency brain oscillations in children: a wavelet-based beamformer study. Brain Res 1274:28-39

64. Yordanova J, Kolev V 1997 Alpha response system in children: changes with age Int J Psychophysiol 26:411-430

65. Okumura A, Kubota T, Tsuji T, Kato T, Hayakawa F, Watanabe K 2006 Amplitude spectral analysis of theta/alpha/beta waves in preterm infants. Pediatr Neurol 34:30-34

66. Vanhatalo S, Kaila K 2006 Development of neonatal EEG activity: from phenom enology to physiology. Semin Fetal Neonatal Med 11:471-478

67. Grieve PG, Isler JR, Izraelit A, Peterson BS, Fifer WP, Myers MM, Stark RI 2008 EEG functional connectivity in term age extremely low birth weight infants. Clin Neurophysiol 119:2712-2720

68. Clarke AR, Barry RJ, McCarthy R, Selikowitz M 2001 Age and sex effects in the EEG: development of the normal child. Clin Neurophysiol 112:806-814

69. Gasser T, Jennen-Steinmetz C, Stroka L, Verleger R, Möcks J 1988 Development of the EEG of school-age children and adolescents. II. Topography. Electroencephalogr Clin Neurophysiol 69:100-109

70. Miskovic V, Schmidt LA, Boyle M, Saigal S 2009 Regional electroencephalogram (EEG) spectral power and hemispheric coherence in young adults born at extremely low birth weight. Clin Neurophysiol 120:231-238

71. Grunau RE, Holsti L, Peters JW 2006 Long-term consequences of pain in human neonates. Semin Fetal Neonatal Med 11:268-275

72. Okumura A, Kubota T, Toyota N, Kidokoro H, Maruyama K, Kato T, Hayakawa F, Watanabe K 2003 Amplitude spectral analysis of maturational changes in delta waves in preterm infants. Brain Dev 25:406-410

73. Tolonen M, Palva JM, Andersson S, Vanhatalo S 2007 Development of the spontaneous activity transients and ongoing cortical activity in human preterm babies Neuroscience 145:997-1006 